\title{
Optimization of ITS Construction Scheme for Road Network under the Restriction of Different Transports' Passenger Person-Kilometers
}

\author{
Ming-wei Li \\ Tourism College of Xinyang Normal University, Xinyang, Henan 464000, China \\ Correspondence should be addressed to Ming-wei Li; 467827811@qq.com
}

Received 7 March 2017; Revised 24 April 2017; Accepted 3 May 2017; Published 11 June 2017

Academic Editor: Ivan Giorgio

Copyright (C) 2017 Ming-wei Li. This is an open access article distributed under the Creative Commons Attribution License, which permits unrestricted use, distribution, and reproduction in any medium, provided the original work is properly cited.

\begin{abstract}
Diversified transport modes and increased personal transportation demands have increased in urban traffic problems such as traffic congestion and environmental pollution. To cope with traffic problems, advanced transportation technologies are being developed as intelligent transportation system (ITS). There is a growing trend to coordinate varying kinds of transportation modes. However, the effective construction and application of ITS in urban traffic can be affected by many factors, such as transport mode. Therefore, how to reasonably construct ITS by consideration of different transport modes' characteristics and requirements is an important research challenge. Additionally, both costs and negative effects must be minimized and application efficiency is required to be optimal in the construction process. To address these requirements, a multiobjective optimization model and a fuzzy selecting optimum model were combined to study the construction scheme based on optimization results. The empirical analysis of Beijing, China, suggested several considerations for improvements to future road network ITS construction with controlled costs. Finally, guidelines are proposed to facilitate ITS construction, improve ITS application efficiency, and transform and innovate strategies to cope with urban traffic.
\end{abstract}

\section{Introduction}

This century has witnessed the increased usage of advanced technology with development of the Internet of things, big data, cloud computing, and the Internet + . Application of these technologies is key to a modern transportation industry. The requirements of transportation are continuing to grow along with the rapid social development and rapid expansion of economic globalization. Thus, traffic development quality and structural requirements have become urgent concerns. The goals of modern traffic technologies are safety assurance, increased efficiency, preserving the environment, and saving energy. Thus, research on the construction of an intelligent transportation system with high application efficiency is an important focus worldwide. However, the effective development and operation of intelligent transportation system (ITS) requires significant planning due to the significant demands and complexity of these systems. This problem is made more complex due to the uncertain operation of different transport modes. Therefore, how to establish a reasonable ITS construction scheme is a major challenge. In this study, passenger person-kilometers was selected as the token indicator. Through the combination of a multiobjective optimization model and a fuzzy selecting optimum model, an optimal ITS construction model is proposed. Next, this combination model was used to study Beijing, China. The goal was to improve both the speed quality and scale benefit of ITS construction, increase the scientific basis for design of ITS construction, and optimize urban traffic with efficiently controlled cost.

\section{Literature Review}

The sharply increasing extent of vehicle ownership and road network traffic pressure in China has increased the conflict between limited traffic resource supply and unlimited demand, resulting in decreased traffic operation efficiency and increased environmental pollution and safety problems, such as the cities of Beijing, Guangzhou, Hangzhou, and Wuhan [1]. Therefore, improvements are needed in the road 
network transport system. Nagurney [2] proposed basic methods of construction and optimization of travel and developed a traffic demand user equilibrium flow optimization model. The urban traffic passenger flow route optimization model was considered as a binary linear programming problem, leading to the proposal of a branch and bound optimal method by Claessens et al. [3]. Then Yang et al. (2005) [4] proposed an urban district traffic generation forecast model to optimize road network traffic based on population and land utilization by forecasting the percentage of return travel demand. Richardson (2005) [5] explored the main indicators that affected sustainable development of network traffic based on existing road network operation, allowing optimization based on feedback information. Lee and Ahn (2005) [6] argued that the dependence degree of work travel to the road network travel layout structure was higher than nonwork travel in Seoul, South Korea. Most studies have focused on the basic characteristics of road network traffic optimization and have not considered the traffic flow involved or the required information technologies.

Traffic flow has been the main indicator for the analysis of road network traffic based on many empirical analyses and can be used for traffic optimization. Bussieck et al. (2004) [7] studied road network construction and used an initial optimization solution that included nonlinear programming. Dheenadayalu et al. (2004) [8] proposed a travel demand optimization model that included the main factors that influence traffic capacity. A microscopic forecast model was built from the perspective of traffic flow by Schadschneider et al. (2005) [9], allowing proposal of traffic congestion optimization solutions. Nandi et al. (2009) [10] first proposed an optimization model from the perspective of transport costs, using the law of universal gravitation to analyze traffic flow status and then the solution of urban passenger transportation optimization was proposed. Monache et al. (2014) [11] argued the problem of roundabout traffic flow from a macroscopic angle using the indicators of total travel and waiting time. The empirical analysis was carried out through annular intersection simulation into a series of $2 \times$ 2 points. A development strategy of feasible supply and public transportation passenger coordination was proposed by Hong (2006) [12] to address the uneven passenger flow distribution feature between satellite towns and a central city. Zhao et al. (2009) [13] argued the importance of bus travel time and a passenger transfer coefficient and performed empirical analysis by constructing an advanced immune genetic algorithm optimization model. Ye and Chen (2010) [14] argued that the constraints of traffic flow capacity existed for a nonpublic transport commuter in Central Business District (CBD) city. The optimal method was proposed using the public transportation commuter proportion as a main indicator based on 53 international famous CBD cities. Previous work has been valuable, but most studies still focus on land utilization and road facilities with little study of the role of advanced science or technology to improve network traffic operation efficiency. Additionally, previous studies have been mainly qualitative description, requiring more detailed quantitative analysis.
Certain subsystems have been studied and there have been attempts at optimization. However, most studies focused on local subsystem construction rather than overall construction. For example, Roncoli et al. (2015) [15] argued the problems of traffic flow control in multilane expressway based on the first-order linear constrained optimal control method by introduction of VACS (Vehicle Automation Communication Systems). The visual traffic system optimization program was developed from the perspective of the travel habits of residents, allowing network traffic dynamic optimization (Goossens et al. (2006) [16] and Créput and Koukam (2007) [17]). Li et al. (2014) [18] proposed that the traffic operation efficiency and service ability in road network could be improved effectively by an intelligent traffic management system (ITMS). The integrated computer aided manufacturing definition (IDEF) method was proposed to verify the improvement efficiency of ITMS on road network traffic, allowing formulation of a road network transport process optimization model. Commins and Nolan (2011) [19] argued that the main factors that affected work travel in the Dublin area in 1996-2006 were travel time, work location, and public transportation. Optimization of the overall process was performed by optimization of the influence factors. The optimization problems of regional service quality standard and traffic system design principle were addressed by Panasyuk et al. (2013) [20], and an optimal combinative model allowing selection of feasible routes was proposed.

The literature review reveals that certain achievements have been made in urban traffic optimization. However, the achievements mainly focus on the construction and optimization of urban road network traffic and focus less on the exploration of ITS. Overall, the limits are as follows: (1) there are relatively few studies on ITS construction, especially for different traffic demands. (2) There is little effective guidance and reference standard for ITS construction in different cities. (3) There is no reasonable ITS construction formulation for policy, technology, capital planning, or other components. Besides, there has been little study of ITS construction based on the real demands of different transport modes. The study reported here was designed to address these problems. ITS construction scheme optimization was performed according to the current development situation and traffic demands. All in all, the results in this work provide important knowledge needed for improved ITS optimization.

\section{Model Formulation}

3.1. Analysis of Optimization Goal. The first step of optimization is to determine a clear optimization goal. In this paper, the optimization goal was defined as ITS construction design with high efficiency application, low construction cost, and good service level. These goals can be met with the following parameters. (1) During operation, the application benefits of ITS are restrained by complex traffic influence factors. (2) There are higher requirements for smooth, safe, and convenient network running. Overall, the efficient improvement of ITS is a major objective. (3) The proportion of different travel modes is influenced by many elements that 
TABLE 1: Decision variables for different traffic modes.

\begin{tabular}{lcccccc}
\hline Traffic mode & Private cars & Bus & Taxi & Rail transit & Bicycle & Walking \\
\hline Passenger person-kilometers (ten thousand $\cdot \mathrm{km})$ & $X_{1}$ & $X_{2}$ & $X_{3}$ & $X_{4}$ & $X_{5}$ & $X_{6}$ \\
\hline
\end{tabular}

must be considered and the main optimization targets must be defined.

3.2. Selection of Optimization Method. Studies of transportation construction optimization utilize many optimization methods (Cakir et al. [21], Chen et al. [22], Cardona-Valdés et al. [23], Che [24], Cintron et al. [25], Kamali et al. [26], Sadjady and Davoudpour [27], Boudahri et al. [28], Bevilacqua et al. [29], and Cheng et al. [30]). After careful analysis of published studies, we selected a multiobjective programming (MOP) method. By referencing the general principle of MOP, the objective function and corresponding constraint conditions were constructed.

The MOP method was first put forward by Charnes and Copper in 1961 [31] and was later improved by Lee [32]. MOP has a wide range of applications in economic management, human resource management, government management, large-scale engineering construction optimization, and others. The general model of a linear programming problem can be expressed as follows:

$$
\begin{array}{ll}
\max & F(x)=C \cdot x \\
\text { S.T. } & A x \leq b \\
& x \geq 0 .
\end{array}
$$

If all $x^{(i)}$ are identical, they are the optimal solution. The formula $V \rightarrow \max _{g(x) \geq 0} F(x)$ and $F(x)=\left\{f_{1}(x), f_{2}(x), \ldots\right.$, $\left.f_{i}(x), \ldots, f_{m}(x)\right\}$ were selected to express the optimization solution. Here, we need to declare only the Euclidean nspaces considered in the paper as follows:

$$
\begin{aligned}
x & =\left(x_{1}, x_{2}, \ldots, x_{n}\right)^{T} \in E^{n}, \\
R & \in E^{n}, \\
F(x) & \in E^{n} .
\end{aligned}
$$

If $x_{0}$ is the optimal solution, then $F\left(x_{0}\right) \geq F(x), \forall x \in R$. Or $x_{0}$ is the noninferior solution and $F(x) \geq F\left(x_{0}\right)$.

There are many common methods to solve MOP problems. However, different optimization goals need suitable methods. If multiple objectives are transformed into a single objective problem, the main target method, weighted sum method, and ideal point method are common methods. If multiple objectives are instead converted into a multiple single objective problem, the priority method, grouping sorting method, and interactive programming approaches are commonly used. Goal programming is used if the target is a nonuniform model. Here, a nonuniform solution method was used according to the characteristics of the ITS optimization target and the goal programming method was proposed for optimizing.

\subsection{Construction of Optimization Model}

\subsubsection{Decision Variables Are Identified}

(A) Research Hypotheses Are Put Forward. The research hypotheses are proposed based on the above analysis.

Hypothesis 1 . The city selected is an isolated system without impacts from other cities.

Hypothesis 2. The characteristics of urban travel conditions and road network structure are confirmed.

Hypothesis 3. The traffic modes include private car, bus, taxi, rail transit, cycling, and walking.

Hypothesis 4. The existing network could meet the requirement of urban transportation.

Hypothesis 5. Each traffic mode has its own ITS subsystems to improve operating efficiency.

(B) Decision Variables Are Chosen. The primary objective of ITS construction scheme optimization is that optimization should be based on the development status of the road network traffic. Next, the most suitable passenger personkilometers for each kind of traffic mode can be determined. Finally, the construction priorities of each subsystem can be set. Therefore, all the passenger person-kilometers serve as optimization decision variables (Table 1), allowing determination of the construction priority of ITS subsystems.

3.3.2. Establishing the Objective Function. Improving both the application efficiency and cost saving is optimization target. However, the targets should be divided into primary and secondary targets according to the rules of the MOP model. The primary target provides the highest benefit and the secondary goal is lowest construction cost. The calculation formulas are as follows:

$$
\begin{aligned}
E_{\mathrm{Efficiency}}^{\max } & =\sum_{j=1}^{n} E X_{j} \times X_{j}, \\
E_{\mathrm{Cost}}^{\min } & =\sum_{j=1}^{n} E C_{j} \times X_{j} .
\end{aligned}
$$

In formula (3), $E_{\mathrm{Efficiency}}^{\max }$ and $E_{\text {Cost }}^{\min }$ are the highest benefit and the lowest cost of ITS construction. $E X_{j}$ and $E C_{j}$ represent the application efficiency and cost efficiency of ITS construction in the traffic mode $j . X_{j}$ is the passenger personkilometers of traffic mode $j$. Based on previous studies, $E X_{j}$ and $E C_{j}$ are defined as given in Table 2. 
TABLE 2: The application and cost efficiency exponent of different traffic modes [33].

\begin{tabular}{lcccccc}
\hline \multirow{2}{*}{ Exponent } & \multicolumn{3}{c}{ Traffic mode } & $X_{4}$ & $X_{5}$ \\
& $X_{1}$ & $X_{2}$ & $X_{3}$ & 0.847 & 0.305 & 0.005 \\
$E X_{j}$ & 0.328 & 0.732 & 0.426 & 0.439 & 0.070 \\
$E C_{j}$ & 0.831 & 0.261 & 0.678 & 0.040 \\
\hline
\end{tabular}

Referencing the construction methods of the objective function, the maximum application efficiency and minimum cost efficiency are obtained as follows:

$$
\begin{aligned}
\max Z_{1}(X)= & 0.328 X_{1}+0.732 X_{2}+0.426 X_{3} \\
& +0.847 X_{4}+0.304 X_{5}+0.005 X_{6}, \\
\min Z_{2}(X)= & 0.831 X_{1}+0.261 X_{2}+0.678 X_{3} \\
+ & 0.439 X_{4}+0.070 X_{5}+0.040 X_{6} .
\end{aligned}
$$

Formula (4) says that one target is seeking maximum value and another is for minimum value. Thus, simultaneous achievement of targets of highest application efficiency and lowest cost is impossible because of the limitation of decision variables. Therefore, coordinate and compromise processing must be carried out to get the best solution.

\subsubsection{Determination of the Constraint Conditions}

(A) Constraint of Residents Travel Demand. Meeting residents' basic travel demands is the top priority of road network traffic. Guided by the optimized construction schemes, the total passenger person-kilometers supplied must satisfy residents' travel demand by all kinds of traffic modes, as shown in the following formula:

$$
\sum_{j=1}^{n} X_{j} \geq D \quad(\text { ten thousand people } \cdot \mathrm{km}) .
$$

In formula (5), D is the total urban travel demand. Two common computing methods can be used, the brief algorithm $\left(D_{1}\right)$ and the four-stage method $\left(D_{2}\right)$, as shown in the following formula:

$$
\begin{aligned}
& D_{1}=X \times M \times \sqrt{\frac{A}{C A}}, \\
& D_{2}=\sum_{i}^{t} \sum_{j}^{t} \sum_{k}^{n} O D_{i j k} \times T_{i j k}
\end{aligned}
$$

(ten thousand people $\cdot \mathrm{km}$ ) .

In formula (6), $X$ is the total resident trip (person-time) and $M$ is the average trip distance in road network traffic $(\mathrm{km}) . A$ is the area of a city site $\left(\mathrm{km}^{2}\right)$ and $C A$ is the total area $\left(\mathrm{km}^{2}\right) . O D_{i j k}$ represents the total trips of traffic mode $k$ between districts $i$ and $j$ (person-time). $T_{i j k}$ is the weighted average trip distance of $O D_{i j k}(\mathrm{~km})$. After comparison of the two methods, $D_{2}$ is relatively complex and data acquisition is more difficult. Therefore, $D_{1}$ is chosen as the indicator.

(B) Road Network Traffic Smooth Constraints. The network average driving speed $(V)$, traffic congestion index (TCI), and average delay time of unit mileage $(T)$ were chosen as the indicators of road network unblocked reliability. The computations are presented as follows:

$$
\begin{aligned}
V & =\frac{\left(M \times \sum_{j=1}^{n}\left(X_{j} / \overline{q_{j}}\right)\right)}{\sum_{j=1}^{n} T_{j}} \geq V^{*}(\mathrm{~km} / \mathrm{h}), \\
\mathrm{TCI} & =\alpha_{i} r_{i}=a_{i} \times \frac{l_{c i}}{L_{i}} \leq \mathrm{TCI}^{*}, \\
T & =\frac{1}{n} \sum_{i=1}^{n}\left(\max \left\{\frac{L / v_{t}-L / v_{0}}{L}, 0\right\}\right) \leq T^{*} \text { (min). }
\end{aligned}
$$

In formula (7), $M$ is the road mileage, $\overline{q_{j}}$ is the average yearly passenger volume of traffic mode $j, \sum_{j=1}^{n} T_{j}$ is the average time of traffic mode $j$ passing the $\operatorname{road} M$, and $V^{*}$ is the expectation of the road network average driving speed. Moreover, $\alpha_{i}$ and $r_{i}$ are the weight and congestion mileage ratio of road $i, l_{c i}$ and $L_{i}$ are the congestion mileage and total mileage of road $i$, and TCI* is the expectation value of the congestion index. $T$ is the average delay time of unit mileage, $T_{i}$ is the delay time of $\operatorname{road} i, T^{*}$ is the expectation value of the average delay time of unit mileage, $L$ is the road mileage, and $v_{t}$ and $v_{0}$ are the actual driving speed and the speed in flow state. Finally, the network average driving speed was chosen as a measurement indicator.

(C) Road Network Traffic Security Constraints. Road traffic safety is not just about transport efficiency and social stability but is also closely connected with economic development. Therefore, ensuring the safety of road network traffic is an important task of ITS construction. The accident rate of unit mileage rate $\left(R_{1}\right)$, car accident death rate $\left(R_{2}\right)$, and the accident rate of unit passenger person-kilometers $\left(R_{3}\right)$ were selected as commonly used indicators as shown in the following formula:

$$
\begin{aligned}
& R_{1}=\sum_{j=1}^{n} \frac{N_{j}}{M_{j}} \leq R_{1}^{*}, \\
& R_{2}=\frac{D}{\sum_{j=1}^{n} n_{j}} \leq R_{2}^{*}, \\
& R_{3}=\frac{D}{\sum_{j=1}^{n} X_{j}} \leq R_{3}^{*} .
\end{aligned}
$$


TABLE 3: Accident rate of unit passenger person-kilometers for different traffic modes.

\begin{tabular}{|c|c|c|c|c|c|c|}
\hline Traffic mode & $X_{1}$ & $X_{2}$ & $X_{3}$ & $X_{4}$ & $X_{5}$ & $X_{6}$ \\
\hline Accident rate of unit passenger person-kilometers & $38.1 \times 10^{-6}$ & $4.3 \times 10^{-6}$ & $28 \times 10^{-6}$ & $4.6 \times 10^{-6}$ & $96.6 \times 10^{-6}$ & $2.4 \times 10^{-6}$ \\
\hline
\end{tabular}

TABLE 4: Energy consumption factor for different traffic modes [34].

\begin{tabular}{lllllcc}
\hline Traffic mode & $X_{1}$ & $X_{2}$ & $X_{3}$ & $X_{4}$ & $X_{5}$ & $X_{6}$ \\
\hline$e_{j}(\mathrm{M} /$ person $\cdot \mathrm{km})$ & 2.3 & 0.3 & 2.4 & 0.1 & 0 & 0 \\
\hline
\end{tabular}

In formula (8), $R_{1}^{*}, R_{2}^{*}, R_{3}^{*}$ are the expectation values of the three indicators. $N_{j}$ and $M_{j}$ are the accident numbers and travel distance, respectively, of traffic mode $j . D$ is the number of traffic accident casualties and $n_{j}$ is the vehicle ownership of traffic mode $j$. Similarly, $R_{3}$ is chosen as the characterization of safety indicator by analysis of the accuracy and ease of access of the indicator data, as well as by ensuring the correlation of the decision variables and constraints. Finally, referring to the death rates statistical result proposed in journal "Motor Vehicle Crash Injury Rates by Mode of Travel, United States: Using Exposure-Based Methods to Quantify Differences" (Beck et al., 2007) [35], the data of accident rate of unit passenger person-kilometers are shown in Table 3.

(D) Green Road Network Traffic Constraint. Green network traffic includes air pollution, noise pollution, and energy consumption. According to the characteristics of the decision variables, the traffic atmospheric pollution saturation and traffic energy consumption were selected as the main indicators using the calculation methods presented as follows:

$$
\begin{aligned}
S & =\left(\frac{P_{a}}{C_{a}}\right) \times 100 \% \leq S^{*}(\%), \\
C_{\text {Energy }} & =\sum_{j=1}^{n} e_{j} \times X_{j} \leq C_{\text {Energy }}^{*} \\
& =E_{\max } \times \text { population }(\mathrm{MJ}) .
\end{aligned}
$$

In formula (9), $S^{*}$ is the expectation of traffic atmospheric pollution saturation, $P_{a}$ is the total traffic atmospheric pollution (mg), and $C_{a}$ is total atmospheric pollutant emission (mg). $C_{\text {Energy }}^{*}$ is the limitation of traffic energy consumption, $E_{\max }$ is the upper limitation of annual per capita energy consumption, Population is a city's total population, and $e_{j}$ $(\mathrm{MJ} /$ perso $\cdot \mathrm{km})$ is the energy consumption factor of traffic mode $j$ (as shown in Table 4). The traffic energy consumption was selected as the green indicator.

3.3.4. The Optimization Model. The optimization model was built according to the general model of MOP and combined with the decision variables, objective function, and constraint conditions. First, the target constraints were proposed as shown in the following formula:

$$
\begin{aligned}
& \sum_{j=1}^{n} E X_{j} \times X_{j} \geq \max Z_{1}(X), \\
& \sum_{j=1}^{n} E C_{j} \times X_{j} \leq \min Z_{2}(X) .
\end{aligned}
$$

In formula (10), $\max Z_{1}(X)$ means that the passenger person-kilometers meets the essential travel demands. $\min Z_{2}(X)$ is the input cost of ITS construction, which means that the cost is controlled to a minimum value. Combined with the system constraints, the MOP optimization model was proposed as follows:

$$
\begin{aligned}
& \min Z=P_{1} * d_{1}^{-}+P_{2} * d_{2}^{+} \\
& \sum_{j=1}^{6}\left(E X_{j} * X_{j}\right)+d_{1}^{-}-d_{1}^{+}=\max Z_{1}(X) \\
& \sum_{j=1}^{6}\left(E C_{j} * X_{j}\right)+d_{2}^{-}-d_{2}^{+}=\min Z_{2}(X) \\
& \sum_{j=1}^{6} X_{j} \geq D \\
& \frac{\left(M \times \sum_{j=1}^{6}\left(X_{j} / \overline{q_{j}}\right)\right)}{\sum_{j=1}^{6} T_{j}} \geq V^{*} \\
& \frac{D}{\sum_{j=1}^{6} X_{j}} \leq R_{3}^{*} \\
& \sum_{j=1}^{6} e_{j} \times X_{j} \leq C_{\text {Energy }}^{*} \\
& X_{j} \geq 0 \quad(j=1,2, \ldots, 6) \\
& d_{t}^{-}, d_{t}^{+} \geq 0 \quad(t=1,2) .
\end{aligned}
$$




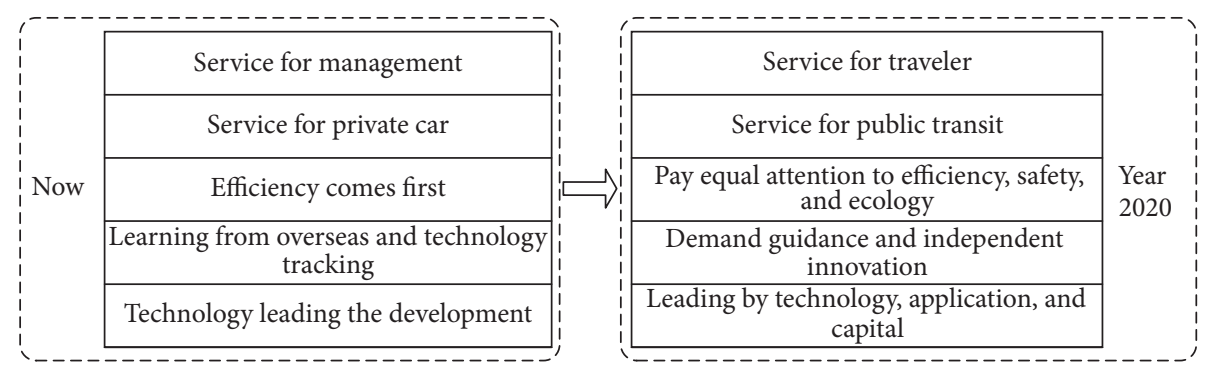

FIGURE 1: The strategic targets of ITS construction in 2020.

In formula (11), $P_{1}$ is the priority factor of ITS application efficiency and $d_{1}^{-}$is the negative deviation variable. $P_{2}$ is the priority factor of input cost and $d_{2}^{+}$is the positive deviation variable. Of these, the priority of $P_{1}$ is higher than $P_{2}$.

3.4. Application of Optimization Results. The basic way of ITS to improve traffic efficiency is to improve the running situation of different traffic modes. At the same time, the optimization proposed in this paper aims to improve passenger person-kilometers for each traffic mode. By analyzing the demands of different traffic modes to various ITS subsystems, the construction priority of the subsystem can be determined based on the optimization results. However, high or low priority is a fuzzy and relative concept with large influence factors, making accurate quantification difficult. Therefore, the fuzzy selecting optimum model was used to achieve priority ranking.

3.4.1. Construction of Fuzzy Selecting Optimum Model. According to the usage of the fuzzy selecting optimum model, the relative optimal matrices of goal maximum and minimum are represented by $R^{\max }=G=\left(g_{1}, g_{2}, \ldots, g_{m}\right)^{T}$ and $R^{\min }=$ $B=\left(b_{1}, b_{2}, \ldots, b_{m}\right)^{T}$. Suppose that $u_{j}$ is the decision $j$ for optimal relative membership degree; then $\left(1-u_{j}\right)$ is the decision $j$ for inferior relative membership degree. $w_{i}$ is the weight of target $i$. Then, the decision $j$ could be expressed as $R_{j}=\left(r_{1 j}, r_{2 j}, \ldots, r_{m j}\right)^{T}$ and the difference between superior decisions is expressed as the generalized weighted distance $d_{j g}$. To study the distance of decision $j$ within superior decision more clearly, the distance is weighted as shown in the following formula:

$$
\begin{aligned}
& d_{j g}=\sqrt[p]{\sum_{i=1}^{m}\left[w_{i}\left(g_{i}-r_{i j}\right)\right]^{p}}, \\
& D_{j g}=u_{j} d_{j g}=u_{j} \times \sqrt[p]{\sum_{i=1}^{m}\left[w_{i}\left(g_{i}-r_{i j}\right)\right]^{p}} \\
& D_{j b}=\left(1-u_{j}\right) d_{j b}=\left(1-u_{j}\right) \times \sqrt[p]{\sum_{i=1}^{m}\left[w_{i}\left(r_{i j}-b_{i}\right)\right]^{p}} .
\end{aligned}
$$

In formula (12), $p$ is the turning parameter, $D_{j g}$ is the weighted distance away from excellent decision, and $D_{j b}$ is weighted distance away from the inferior decision. In order to solve the optimal value of $u_{j}$, the criterion of $\min \left\{Z\left(u_{j}\right)\right\}=$ $\min \left\{D_{j g}^{2}+D_{j b}^{2}\right\}$ was built. If we order $Z\left(u_{j}\right) / d\left(u_{j}\right)=0$, then formula (13) is achieved. Finally, the prioritization would be determined according to the values of $u_{j}$ :

$$
\begin{aligned}
& u_{j} \\
& =\frac{1}{1+\left[\sum_{i=1}^{m}\left[w_{i}\left(g_{i}-r_{i j}\right)\right]^{p} / \sum_{i=1}^{m}\left[w_{i}\left(r_{i j}-b_{i}\right)\right]^{p}\right]^{2 / p}}, \\
& j=1,2, \ldots, n .
\end{aligned}
$$

\section{Empirical Analysis: A Case Study of Beijing, China}

4.1. Optimization Target of ITS Construction. By referring to the "Transportation Industry Intelligent Traffic Development Strategy (2012-2020)," we know that the following targets will be realized in some big cities in China, such as Beijing, Shanghai, Guangzhou, and Shenzhen, as shown in Figure 1.

Therefore, the year 2020 was chosen as the planning year considering the optimization effectiveness and data availability. Beijing was chosen as the case city.

\subsection{Constraint Conditions of ITS Construction Optimization}

4.2.1. Resident Travel Demand Constraint in Beijing. Data was obtained from the journal "Research on the Development Prospect of Low Carbon Traffic in Beijing" (Liu, 2010) [36]. Then the value of travel demand is shown as follows:

$$
\begin{aligned}
D & =X \times M \times \sqrt{\frac{A}{C A}}=6100 \times 9.3 \times \sqrt{\frac{1650}{1254}} \\
& =65073.8 .
\end{aligned}
$$

4.2.2. Road Network Traffic Smooth Constraint in Beijing. Using data published by the Beijing traffic development research center, the travel time is shown in Table 5. 
TABLE 5: Road network traffic runtime of Beijing in 2020.

\begin{tabular}{lcccccc}
\hline Traffic mode & $X_{6}$ & $X_{5}$ & $X_{1}$ & $X_{3}$ & $X_{2}$ \\
\hline Percentage of trip (\%) & $1.5-2.5$ & $3.4-4.6$ & $22.4-28.8$ & $6.2-7.7$ & $26.0-33.6$ & $34.8-39.4$ \\
Average time (min/every time) & 18 & 24 & 43 & 39 & 63 & 75 \\
\hline
\end{tabular}

TABLE 6: The maximum and the minimum passenger person-kilometers.

\begin{tabular}{lcccccc}
\hline Traffic mode & $X_{1}$ & $X_{2}$ & $X_{3}$ & $X_{4}$ & $X_{5}$ \\
\hline$X_{\max }$ & 16338.24 & 19061.28 & 4368.21 & 22351.62 & 2609.58 & 1418.25 \\
$X_{\min }$ & 12707.52 & 14749.8 & 3517.26 & 19742.04 & 1928.82 & 850.95 \\
\hline
\end{tabular}

A weighting algorithm is used to forecast the road network average travel time. $T=w t=\left(w_{1}, w_{2}, \ldots, w_{n}\right)\left(t_{1}\right.$, $\left.t_{2}, \ldots, t_{n}\right)=57.54$ (minutes). Here formula (15) is achieved:

$$
\begin{aligned}
& \left(2.43 \times 10^{-4}\right) \times\left[\left(\frac{X_{1}}{3000}+\frac{X_{2}}{7500}+\frac{X_{3}}{3000}+\frac{X_{4}}{30000}\right.\right. \\
& \left.\left.+\frac{X_{5}}{1650}+\frac{X_{6}}{1100}\right) \times 10^{4}\right] \geq V^{*}=\frac{U}{T}=\frac{22.92}{(57.75 / 60)} \\
& =23.81
\end{aligned}
$$

4.2.3. Road Network Traffic Security Constraint in Beijing. The "traffic congestion easing plan in Beijing (2015-2020)" [37] showed that the road network unit passenger personkilometers accident death rate should be controlled to 1.2 (people/ten thousand $\cdot \mathrm{km}$ ). That is to say, $R_{3} \leq R_{3}^{*}=1.2$ (people/ten thousand $\cdot \mathrm{km}$ ).

\subsubsection{Road Network Traffic Green Constraint in Beijing.} Carlsson-Kanyama et al. [38] argued that the supply per capita should be at least $11000 \mathrm{MJ} /$ year as the basic daily activity energy. However, the supply per capita in Beijing is lower. Therefore, based on Ma et al. (2008) [39], the per capita traffic energy consumption was set as $18.14 \mathrm{MJ} /$ person, giving the following formula:

$$
\begin{aligned}
& \left(2.3 X_{1}+0.3 X_{2}+2.4 X_{3}+0.1 X_{4}+0 X_{5}+0 X_{6}\right) \times 10^{4} \\
& \leq C_{\text {Energy }}^{*}=18.14 \times 1800 \times 10^{4} \\
& \quad=32652 \times 10^{4}(\mathrm{MJ})
\end{aligned}
$$

4.2.5. Total Investment of ITS Construction. Because the total investment of ITS construction in 2020 is not available, the time series model prediction method was used to forecast the investment based on the secondary sliding average algorithm. The specific data and stationary test can refer to the paper entitled "Research on the Evaluation Period of ITS Application Effects Based on VAR Model-takes Beijing as an example" (Li et al., 2015) [40]. Finally, the predication value was obtained as follows:

$$
\begin{aligned}
\widehat{y}_{2020}(2) & =2.55+0.16 * 6=3.51 \text { (billion } \mathrm{RMB}) \\
& =35100(\text { million } \mathrm{RMB})=C^{*} .
\end{aligned}
$$

\subsection{Calculation and Analysis of Optimization Results}

4.3.1. Calculation of the Optimization Model. First, the maximum and the minimum passenger person-kilometers borne by each traffic mode were calculated according to the composition proportion (Table 6).

Second, $E_{\text {Cost }}^{\min } \leq \min Z_{2}(X)=35100$ and $E_{\text {Efficiency }}^{\max } \geq$ $\max Z_{1}(X)=40907.98$. Finally, the residents demand amount is 65073.8 (ten thousand people. $\mathrm{km}$ ) according to formula (14). Next, the Goal Program-running (GP) subroutine in WINQSB software was used for calculation and the calculation results are as follows: $X_{1}=16338.24 ; X_{2}=$ $19061.28 ; X_{3}=4368.21 ; X_{4}=22351.62 ; X_{5}=2586.22 ; X_{6}=$ $850.95 ; d_{1}^{-}=0 ; d_{2}^{+}=6.45 ; P_{1}=24.33 ; P_{2}=6.45$. The results show that the value of passenger person-kilometers in Beijing should satisfy the value in Table 7.

4.3.2. Analysis of the Optimization Scheme. The fuzzy selecting optimum model is applied to analyze the construction priority decisions of ITS subsystem as follows: (1) determining the priority of influencing factors: according to multiobjective optimization results, the factors influencing the construction priority of each subsystem are the passenger person-kilometers; (2) determining the indicator weight: to determine the weight of each indicator is difficult. Here, the specialist consultation method is proposed to obtain the weight (opinion of invited experts mainly from the Ministry of Transport Research Institute Information Center of China and the Research Center of Intelligent Transportation of China) given the application characteristics and financial evaluation features of each subsystem [41]; and (3) determining the construction priority of each subsystem: the construction priority of each ITS subsystem could be achieved by incorporating the data into the fuzzy selecting optimum model, as shown in Table 8.

\section{Conclusion}

In this paper, current problems of ITS construction scheme optimization were discussed. Then, the MOP optimization model was constructed to guarantee the lasting efficiency of ITS construction with passenger person-kilometers defined as the decision variable. Next, the constraint conditions were established and the optimized analysis was performed. The network structure optimization analysis of ITS construction 
TABLE 7: The passenger person-kilometers of each traffic mode in Beijing.

\begin{tabular}{lcccccc}
\hline Traffic mode & $X_{1}$ & $X_{2}$ & $X_{3}$ & $X_{4}$ & $X_{5}$ & $X_{6}$ \\
\hline Passenger person-kilometers & 16338.24 & 19061.28 & 4368.21 & 22351.62 & 2586.22 & 850.95 \\
\hline
\end{tabular}

TABLE 8: The construction priority suggestion of ITS subsystems in Beijing.

\begin{tabular}{|c|c|c|}
\hline Application area & Subsystem & The comprehensive priority \\
\hline \multirow{4}{*}{ Road transport integrated management system } & Road transport administrative management system & 计的访 \\
\hline & Road transport safety management system & 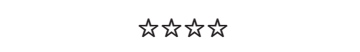 \\
\hline & Operating vehicle GPS monitoring system & 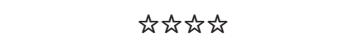 \\
\hline & Transport of dangerous goods regulation system & 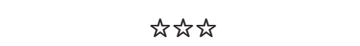 \\
\hline \multirow{4}{*}{ Road traffic control system } & Road traffic monitoring system & 论坛场动 \\
\hline & Traffic signal control system & 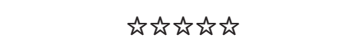 \\
\hline & Traffic emergency management system & 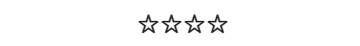 \\
\hline & Traffic enforcement and illegal management system & 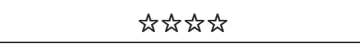 \\
\hline \multirow{4}{*}{ Electronic toll collection system } & Electronic parking fees & 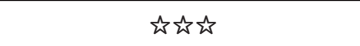 \\
\hline & The municipal transportation "all-in-one-card" & 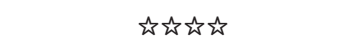 \\
\hline & Highway charge system & 论论证 \\
\hline & Passage stations networked ticketing system & 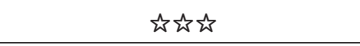 \\
\hline \multirow{4}{*}{ Traffic information service system } & Traffic information collection system & 论坛访 \\
\hline & Traffic information processing system & 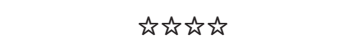 \\
\hline & Traffic information publishing system & 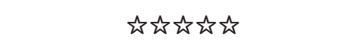 \\
\hline & Traffic guidance system & 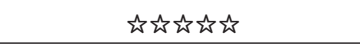 \\
\hline \multirow{5}{*}{ Intelligent public traffic system } & Bus information service system & 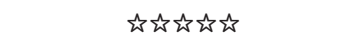 \\
\hline & Bus monitoring and scheduling system & 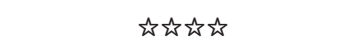 \\
\hline & Public transport emergency management system & 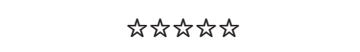 \\
\hline & Transit network planning decision support system & 计场 \\
\hline & Taxi management and service system & 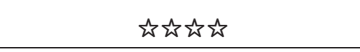 \\
\hline \multirow{2}{*}{ Parking management and service system } & Parking management and service system & 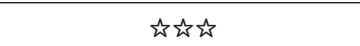 \\
\hline & Park-and-ride management and service system & 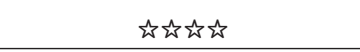 \\
\hline \multirow{4}{*}{ Road network traffic evaluation system } & Traffic data acquisition and analysis system & 计动放 \\
\hline & Network traffic prediction system & 论论场 \\
\hline & Road network comprehensive evaluation system & 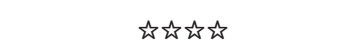 \\
\hline & Urban road network traffic simulation system & 式施放 \\
\hline
\end{tabular}

Note. The more the number of “汸," the higher priority level of the subsystem.

was achieved with a fuzzy selecting optimum model. Furthermore, a set of relatively optimal ITS construction plans were proposed by sorting the priority of each subsystem. These results in the paper can improve efficiency of ITS construction and lower investment cost. Overall, this improved strategy should promote effectively the coordinated development of urban traffic. Finally, the empirical analysis results revealed that both the improvement of public transportation priority and private car efficiency are main targets of ITS construction.

However, there are limits of this study. For example, differences in ITS construction requirements in different cities will cause construction differences and differences in key technology and the development of ITS. Limits of the accuracy and acquisition of the statistics data allow study of only larger cities with strong demands for ITS. ITS will be incorporated into plans for more and more cities with the acceleration of urbanization and optimization of ITS construction should be tailored to meet the needs of each city.

\section{Conflicts of Interest}

The author declares that there are no conflicts of interest to declare regarding this work.

\section{Acknowledgments}

This work was supported by the Research on the Performance Appraisal System and its Application of Transport Industry Informatization sponsored by the Chinese Ministry of Transport (2015364811070) and the Nanhu Scholars Program for Young Scholars of XYNU (2017).

\section{References}

[1] Scott, map. "Analysis Report of China’s Urban Traffic", [EB/OL]. http://report.amap.com/index.do, 2016-01-01/2016-12-31.

[2] A. Nagurney, "Congested urban transportation networks and emission paradoxes," Transportation Research Part D: Transport and Environment, vol. 5, no. 2, pp. 145-151, 2000. 
[3] M. T. Claessens, N. M. Van Dijk, and P. J. Zwaneveld, "Cost optimal allocation of rail passenger lines," European Journal of Operational Research, vol. 110, no. 3, pp. 474-489, 1998.

[4] M. Yang, X. Chen, W. Wang, and W. Y. Li, “Trip generation forecasting model of new district based on urban population and land use," Journal of Southeast University, vol. 9, no. 5, pp. 815-819, 2005.

[5] B. C. Richardson, "Sustainable transport: Analysis frameworks," Journal of Transport Geography, vol. 13, no. 1, pp. 29-39, 2005.

[6] C.-M. Lee and K.-H. Ahn, "Five new towns in the Seoul metropolitan area and their attractions in non-working trips: Implications on self-containment of new towns," Habitat International, vol. 29, no. 4, pp. 647-666, 2005.

[7] M. R. Bussieck, T. Lindner, and M. E. Lubbecke, "A fast algorithm for near cost optimal line plans," Mathematical Methods of Operations Research, vol. 59, no. 2, pp. 205-220, 2004.

[8] Y. Dheenadayalu, B. Wolshon, and C. Wilmot, "Analysis of link capacity estimation methods for urban planning models," Journal of Transportation Engineering, vol. 130, no. 5, pp. 568575, 2004.

[9] A. Schadschneider, W. Knospe, L. Santen, and M. Schreckenberg, "Optimization of highway networks and traffic forecasting," Physica A: Statistical Mechanics and Its Applications, vol. 346, no. 1-2, pp. 165-173, 2005.

[10] A. K. Nandi, K. Bhattacharya, and S. S. Manna, "An optimal network for passenger traffic," Physica A: Statistical Mechanics and its Applications, vol. 388, no. 17, pp. 3651-3656, 2009.

[11] M. L. Monache, L. L. Obsu, P. Goatin, and S. M. Kasa, “Traffic flow optimization on roundabouts," Procedia - Social and Behavioral Sciences, vol. 111, no. 5, pp. 127-136, 2014.

[12] E. Hong, Analysis on passenger flow characteristics and supply strategy between satellite town and central city, Southwest Jiao tong University Degree Thesis, 2009.

[13] J. Zhao, S. Zhao, and Y. Lin, "Literature review on the optimism of transit network and scheduling," Transpot Standardization, vol. 24, pp. 94-98, 2009.

[14] P. Ye and X. Chen, "Commuting travel patterns for mega CBDs around the world," Urban Transportation of China, vol. 8, no. 1, pp. 60-66, 2010.

[15] C. Roncoli, M. Papageorgiou, and I. Papamichail, "Traffic flow optimisation in presence of vehicle automation and communication systems-part II: optimal control for multi-lane motorways," Transportation Research Part C: Emerging Technologies, vol. 57, pp. 260-275, 2015.

[16] J.-W. Goossens, S. van Hoesel, and L. Kroon, "On solving multi-type railway line planning problems," European Journal of Operational Research, vol. 168, no. 2, pp. 403-424, 2006.

[17] J.-C. Créput and A. Koukam, "Interactive meshing for the design and optimization of bus transportation networks," Journal of Transportation Engineering, vol. 133, no. 9, pp. 529-538, 2007.

[18] B. Li, M. Zou, and Y. Guo, "Business Process Analysis and Optimization on Road Traffic Law Enforcement of the Beijing Intelligent Traffic Management," Procedia - Social and Behavioral Sciences, vol. 138, no. 14, pp. 748-756, 2014.

[19] N. Commins and A. Nolan, "The determinants of mode of transport to work in the Greater Dublin Area," Transport Policy, vol. 18, no. 1, pp. 259-268, 2011.

[20] M. Panasyuk, E. Pudovik, and M. Sabirova, "Optimization of regional passenger bus traffic network," Procedia Economics and Finance, vol. 5, pp. 589-596, 2013.
[21] B. Cakir, F. Altiparmak, and B. Dengiz, "Multi-objective optimization of a stochastic assembly line balancing: A hybrid simulated annealing algorithm," Computers and Industrial Engineering, vol. 60, no. 3, pp. 376-384, 2011.

[22] C.-L. Chen, T.-W. Yuan, and W.-C. Lee, "Multi-criteria fuzzy optimization for locating warehouses and distribution centers in a supply chain network," Journal of the Chinese Institute of Chemical Engineers, vol. 38, no. 5-6, pp. 393-407, 2007.

[23] Y. Cardona-Valdés, A. Álvarez, and J. Pacheco, "Metaheuristic procedure for a bi-objective supply chain design problem with uncertainty," Transportation Research, Part B: Methodological, vol. 60, pp. 66-84, 2014.

[24] Z. H. Che, "A particle swarm optimization algorithm for solving unbalanced supply chain planning problems," Applied Soft Computing Journal, vol. 12, no. 4, pp. 1279-1287, 2012.

[25] A. Cintron, A. R. Ravindran, and J. A. Ventura, "Multi-criteria mathematical model for designing the distribution network of a consumer goods company," Computers \& Industrial Engineering, vol. 58, no. 4, pp. 584-593, 2010.

[26] A. Kamali, Fatemi G., and F. Jolai, "A multi-objective quantity discount and joint optimization model for coordination of a single-buyer multi-vendor supply chain," Computers and Mathematics with Applications, vol. 62, no. 8, pp. 3251-3269, 2011.

[27] H. Sadjady and H. Davoudpour, "Two-echelon, multi-commodity supply chain network design with mode selection, leadtimes and inventory costs," Computers \& Operations Research, vol. 39, no. 7, pp. 1345-1354, 2012.

[28] F. Boudahri, Z. Sari, and M. Bennekrouf, "Renovation of a distribution network of poultry products: application city of Tlemcen," in Proceedings of the International Conference on Logistics, pp. 115-121, IEEE, Tunisia, June 2011.

[29] V. Bevilacqua, N. Costantino, M. Dotoli, M. Falagario, and F. Sciancalepore, "Strategic design and multi-objective optimisation of distribution networks based on genetic algorithms," International Journal of Computer Integrated Manufacturing, vol. 25, no. 12, pp. 1139-1150, 2012.

[30] X. Cheng, P. Du, Z. He, and Z. Yang, "Approach of intelligent traffic signal control for isolated intersection," Journal of Systems Engineering, vol. 20, no. 1, pp. 23-29, 2005.

[31] A. Charnes, W. Cooper, K. Lewis A et al., A Multi-Objective Model for Planning Equal Employment Opportunities, vol. 33, Springer, Berlin Heidelberg, Germany, 1975.

[32] S. M. Lee, Goal Programming Methods for Multiple Objective Integer Programs, American Institute of Industrial Engineers, Atlanta, Ga, USA, 1979.

[33] H. Jun, Y. Pei, and X. Shen, "Double-goal optimization model of ecology and utility for urban passenger traffic structure," Journal of Highway and Transportation Research and Development, vol. 07, pp. 139-143, 2012.

[34] S. Lv, F. Tjan, and X. Li, "Study on the optimized model of urban passenger traffic structure," Journal of Highway and Transportation Research and Development, vol. 24, no. 7, pp. 117120, 2004.

[35] L. F. Beck, A. M. Dellinger, and M. E. O’Neil, "Motor vehicle crash injury rates by mode of travel, United States: using exposure-based methods to quantify differences," American Journal of Epidemiology, vol. 166, no. 2, pp. 212-218, 2007.

[36] W. Y. Liu, "Research on the development prospect of low carbon traffic in beijing," Comprehensive Transportation, vol. 09, pp. 3739, 2010. 
[37] Beijing Municipal commission of Transport, Traffic Congestion Easing plan in Beijing (2015-2020), Beijing Municipal commission of Transport.

[38] A. Carlsson-Kanyama, M. P. Ekström, and H. Shanahan, "Food and life cycle energy inputs: Consequences of diet and ways to increase efficiency," Ecological Economics, vol. 44, no. 2-3, pp. 293-307, 2003.

[39] J. Ma, L. Wu, and Z. Ding, "The impact analysis of passenger traffic modes on the urban sustainable development," Journal of Nanjing Forest University, vol. 32, no. 6, pp. 102-106, 2008.

[40] M.-W. Li, J. Yun, and N. Liu, "Research on the evaluation period of its application effects based on VAR model-takes Beijing as an example," Modernization of Management, vol. 4, pp. 115-117, 2015.

[41] M.-W. Li, J. Yun, and N. Liu, "Calculating the contribution rate of intelligent transportation system in improving urban traffic smooth based on advanced DID model," Mathematical Problems in Engineering, vol. 2015, Article ID 564230, 12 pages, 2015. 


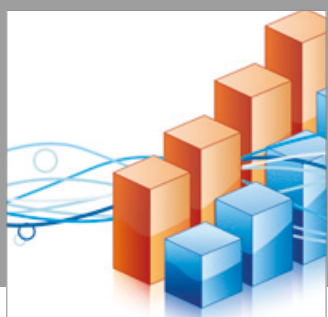

Advances in

Operations Research

vatersals

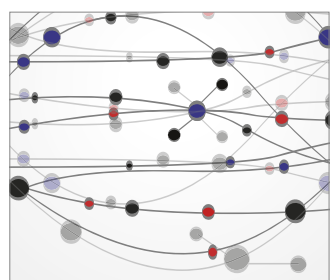

\section{The Scientific} World Journal
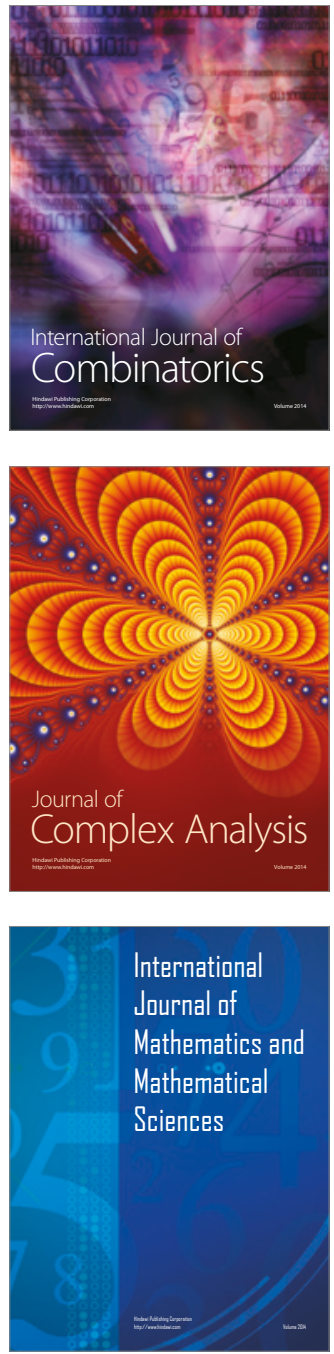
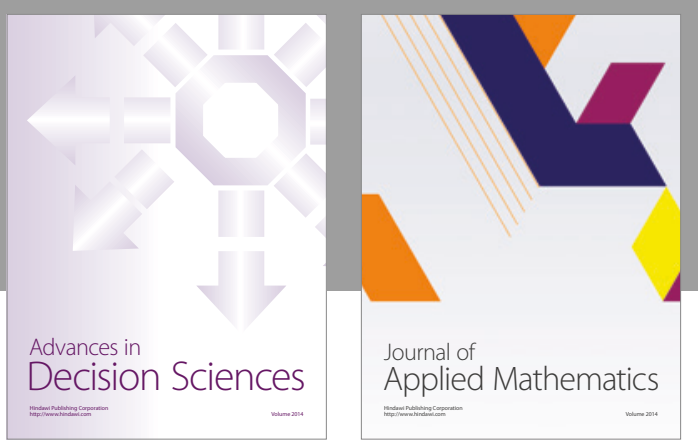

Algebra

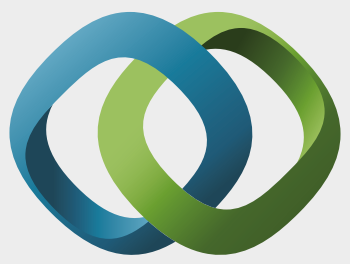

\section{Hindawi}

Submit your manuscripts at

https://www.hindawi.com
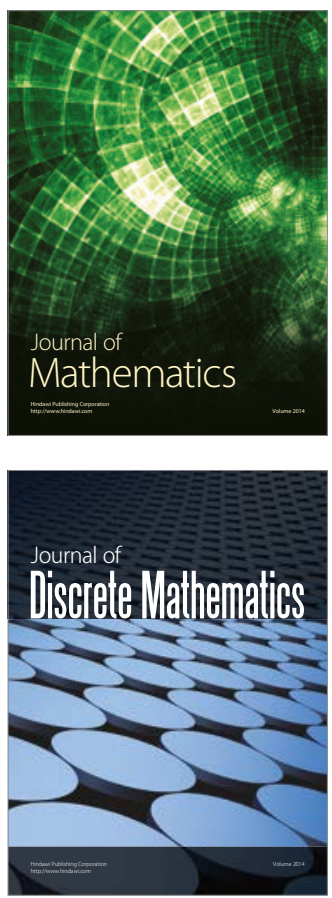

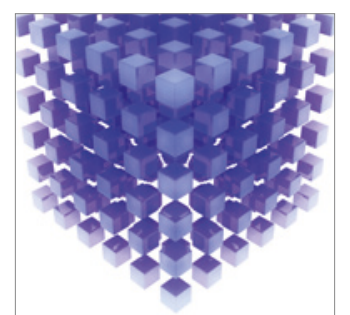

Mathematical Problems in Engineering
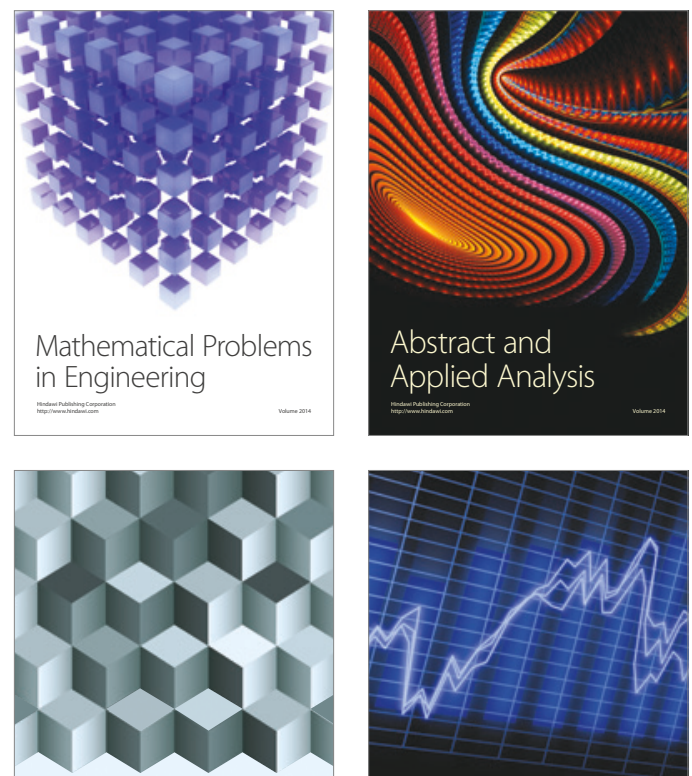

Journal of

Function Spaces

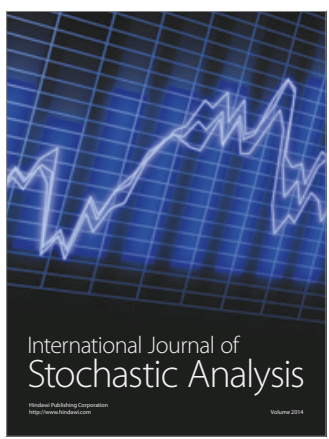

Probability and Statistics
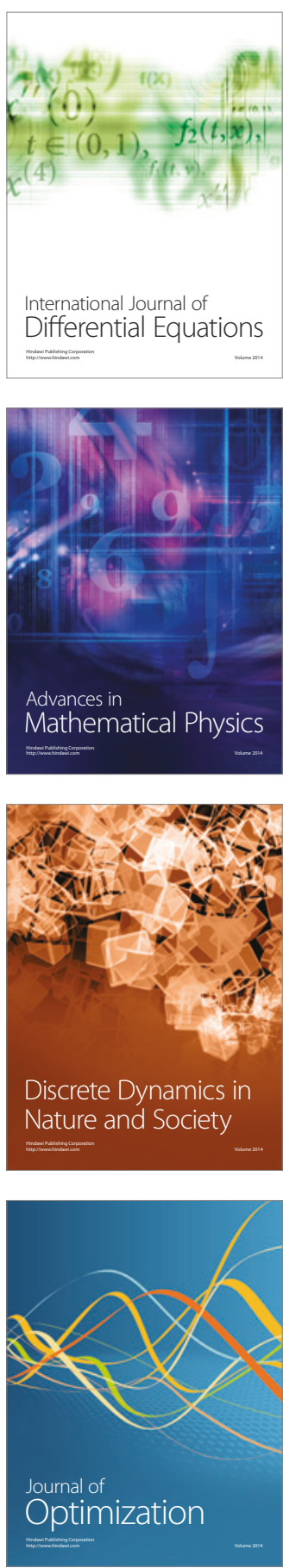